\title{
Composição centesimal e análise sensorial da carne de ovinos Morada Nova alimentados com dietas contendo melão em substituição ao milho
}

\section{Roberto Germano Costa ${ }^{1}$, Cláudio Adriano Correia de Lima ${ }^{2}$, Ariosvaldo Nunes de Medeiros ${ }^{1}$, Guilherme Ferreira da Costa Lima ${ }^{2}$, Carlo Aldrovandi Torreão Marques ${ }^{3}$, Rita de Cássia Ramos do Egypto Queiroga ${ }^{1}$}

\footnotetext{
1 Universidade Federal da Paraíba - UFPB. Bolsista do CNPq.

${ }^{2}$ Empresa de Pesquisa Agropecuária do Rio Grande do Norte - EMPARN.

3 Universidade Federal do Piauí - UFPI, Campus de Bom Jesus-PI.
}

RESUMO - Objetivou-se avaliar a influência da adição de melão em substituição ao milho moído em dietas sobre a composição centesimal e análise sensorial da carne de ovinos da raça Morada Nova. Foram utilizados 20 animais da raça Morada Nova, machos não-castrados, com peso vivo médio inicial de $15 \mathrm{~kg}$, distribuídos em delineamento inteiramente ao acaso para avaliação de quatro níveis (0, 30, 60 e 100\%) de inclusão de melão em substituição ao milho moído, cada um avaliado com cinco repetições. Para determinar a composição centesimal da carne, utilizou-se o músculo semimembranosus. Com o músculo longissimus dorsi, procedeu-se à análise sensorial quantificando, por intermédio de notas, os atributos de sabor, odor, suculência, maciez e aparência global. As análises dos dados não apresentaram diferenças significativas para a composição centesimal (umidade, proteína, lipídio e matéria mineral). Na análise sensorial, a suculência apresentou comportamento quadrático, com ponto de máximo de 5,18, e as demais qualidades organolépticas (odor, sabor, maciez e aparência global) não foram influenciadas pela inclusão de melão em substituição ao milho nas dietas. A utilização de melão em substituição ao milho em dietas para ovinos Morada Nova não afeta as principais qualidades organolépticas da carne.

Palavras-chave: confinamento, qualidade da carne, raça nativa, subproduto agrícola

\section{Centesimal composition and sensorial analysis of Morada Nova lambs fed diets containing melon fruit in substitution of corn grain}

\begin{abstract}
The objective of this trial was to evaluate the influence of the addition of melon fruit replacing ground corn in diets on the centesimal composition and sensory analysis of meat from Morada Nova lambs. Twenty Morada Nova males with average weight of $15 \mathrm{~kg}$ were distributed in a completely randomized design with four increasing levels $(0,30$, 60 and $100 \%$ ) of melon in substitution of ground corn, each one with five replications. To determine the chemical composition of meat, the semimembranosus muscle was used. With the muscle longissimus dorsi sensory analysis, the attributes of taste, odor, juiciness, softness and overall appearance were conducted by quantifying, by means of scoring. Data analysis showed no significant differences in proximate composition (moisture, protein, lipid and ash). At the sensory analysis, juiciness showed quadratic response with a maximum peak of 5.18 and the other organoleptic qualities (flavor, tenderness and overall appearance) were not affected by the inclusion of melon replacing corn in diets. The use of melon in diets for Morada Nova sheep diets does not affect the main organoleptic qualities of meat.
\end{abstract}

Key Words: breed native, agriculture residue, feedlot, meat quality

\section{Introdução}

A escassez de forragem no semiárido ocorre na maior parte do ano, constituindo-se provavelmente no maior desafio enfrentado pela pecuária desta região. Assim, a utilização de subprodutos da agroindústria pode diminuir os efeitos da época seca nos animais e reduzir os gastos com alimentação, uma vez que o maior custo de produção de cordeiros para o abate decorre da alimentação (Caparra et al., 2006; Gonzaga Neto et al., 2006). A utilização desses subprodutos destaca-se como componentes de dietas para ruminantes e o uso desses alimentos pode proporcionar excelentes ganhos de peso e também interferir na qualidade da carne.

O cultivo de melão na região semiárida brasileira é uma das explorações sob regime de irrigação de maior expressão socioeconômica, sobretudo nos estados de Pernambuco, Bahia, Paraíba, Ceará e Rio Grande do Norte(Dias et al., 1998). 
A comercialização da produção, na sua totalidade, acontece na forma de fruta fresca, que é a forma de consumo mais comum. Os mercados nacional, regional e local consomem cerca de $70 \%$ da produção e o mercado externo cerca de $20 \%$, de modo que os $10 \%$ restantes são considerados refugo. Com os altos índices de produtividade alcançados, a quantidade de refugo em disponibilidade pode ser estimada em 34,950 toneladas (Manterola et al., 1992). Esse produto tem sido uma opção para a suplementação de ruminantes no semiárido, devido à sua disponibilidade na região e por ser rico em carboidratos não-fibrosos e água.

Fatores como raça, ambiente e dieta interferem na composição centesimal da carne (Sañudo et al., 2000). Quando comparada à quantidade de lipídios encontrados na carne bovina, suína e de frango, a carne ovina torna-se uma opção para o consumidor que procura carne com baixo teor de lipídios. Um dos maiores desafios da ovinocultura consiste na produção de carnes com alto padrão de qualidade, tendo em vista a preferência do consumidor por carnes macias, saborosas, suculentas e com pouca gordura (Madruga, 2004). O consumidor costuma avaliar a qualidade da carne por etapas: em princípio pela cor da carne e da gordura de cobertura, depois por aspectos relativos ao processamento e, finalmente, pelas características de palatabilidade, suculência e maciez (Costa et al., 2002).

As características organolépticas sempre prevalecem às nutricionais, uma vez que definem o grau de qualidade, ou seja, o preço de mercado desses animais (Camargo et al., 1986). A análise sensorial é um processo de julgamento extremamente complexo (Osório, 2005) e que inclui análise das propriedades: odor, sabor, maciez, suculência e aceitação.

Este trabalho foi realizado com o objetivo de avaliar os efeitos da adição de melão em substituição ao milho moído sobre a composição centesimal e as características sensoriais da carne de ovinos Morada Nova.

\section{Material e Métodos}

O experimento foi conduzido no período de janeiro a maio de 2006, no município de Pedro Avelino-RN, na Estação Experimental de Terras Secas, pertencente à Empresa de Pesquisa Agropecuária do Rio Grande do Norte AS -EMPARN, localizada na mesorregião do Mato Grande, situada a $5^{\circ} 33^{\prime}$ de latitude sul e $36^{\circ} 22^{\prime}$ de longitude oeste. O clima, de acordo com classificação de GAUSSEN, é do tipo $4^{\mathrm{a}} \mathrm{Th}$, ou seja, tropical quente de seca acentuada, com 7 a 8 meses secos, com precipitação média anual de $473 \mathrm{~mm}$.

Foram utilizados 20 ovinos machos não-castrados da raça Morada Nova, variedade vermelha, com idade média de 6 meses, peso inicial médio de $15 \mathrm{~kg}$ confinados em baias individuais com dimensões de $1,2 \times 4 \mathrm{~m}$, as quais tinham $2 \mathrm{~m}$ de piso cimentado (coberto com telhas de cerâmicas) e 2 m de chão batido (solário), providas de comedouros, bebedouros e saleiros. Os animais foram pesados, identificados, vermifugados e distribuídos em delineamento inteiramente casualizado com quatro tratamentos e cinco repetições. As pesagens ocorreram a cada sete dias, desde o início do experimento até alcançarem o peso pré-estabelecido de abate ( $25 \mathrm{~kg})$.

As dietas experimentais (Tabela 1) continham em média $16 \%$ de proteína bruta (PB) e eram constituídas de feno de capim-elefante, concentrado, constituído de farelo de milho, farelo de soja e torta de algodão e por diferentes níveis de melão, doados por empresas exportadoras de melão, na relação de 60:40 de concentrado e volumoso respectivamente. Além desses alimentos, utilizou-se mistura mineral. As rações foram formuladas de acordo com o NRC (1985) para atender às exigências nutricionais de animais com ganho diário de $150 \mathrm{~g} /$ animal/dia (Tabela 2).

As determinações de matéria seca(MS), matéria mineral (MM), proteína bruta (PB) e extrato etéreo (EE) foram feitas segundo metodologia descrita por Silva \& Queiroz (2002). Para determinação das frações da parede celular, fibra em

Tabela 1 - Composição bromatológica dos ingredientes das dietas

\begin{tabular}{|c|c|c|c|c|c|}
\hline \multirow[t]{2}{*}{ Composição bromatológica (\%) } & \multicolumn{5}{|c|}{ Ingrediente } \\
\hline & Milho moído & Melão & Farelo de soja & Torta de algodão & Feno de capim-elefante \\
\hline Matéria seca & 89,35 & 7,28 & 89,62 & 94,14 & 89,64 \\
\hline Matéria mineral & 1,38 & 9,30 & 6,95 & 4,92 & 7,49 \\
\hline Matéria orgânica & 98,62 & 90,70 & 93,05 & 95,08 & 92,51 \\
\hline Proteína bruta & 7,67 & 11,58 & 43,46 & 25,84 & 4,28 \\
\hline Extrato etéreo & 3,19 & 7,62 & 3,23 & 9,60 & 0,80 \\
\hline Fibra em detergente neutro & 16,00 & 20,58 & 26,76 & 54,31 & 78,88 \\
\hline Fibra em detergente ácido & 10,01 & 16,68 & 10,73 & 31,62 & 50,46 \\
\hline Carboidratos não-fibrosos & 87,76 & 69,94 & 46,36 & 59,64 & 87,43 \\
\hline Carboidratos totais & 71,76 & 49,36 & 19,60 & 5,33 & 8,55 \\
\hline Lignina & 1,27 & 5,86 & 1,23 & 4,18 & 5,26 \\
\hline
\end{tabular}


Tabela 2 - Composição percentual e bromatológica das dietas experimentais contendo melão em substituição ao milho moído

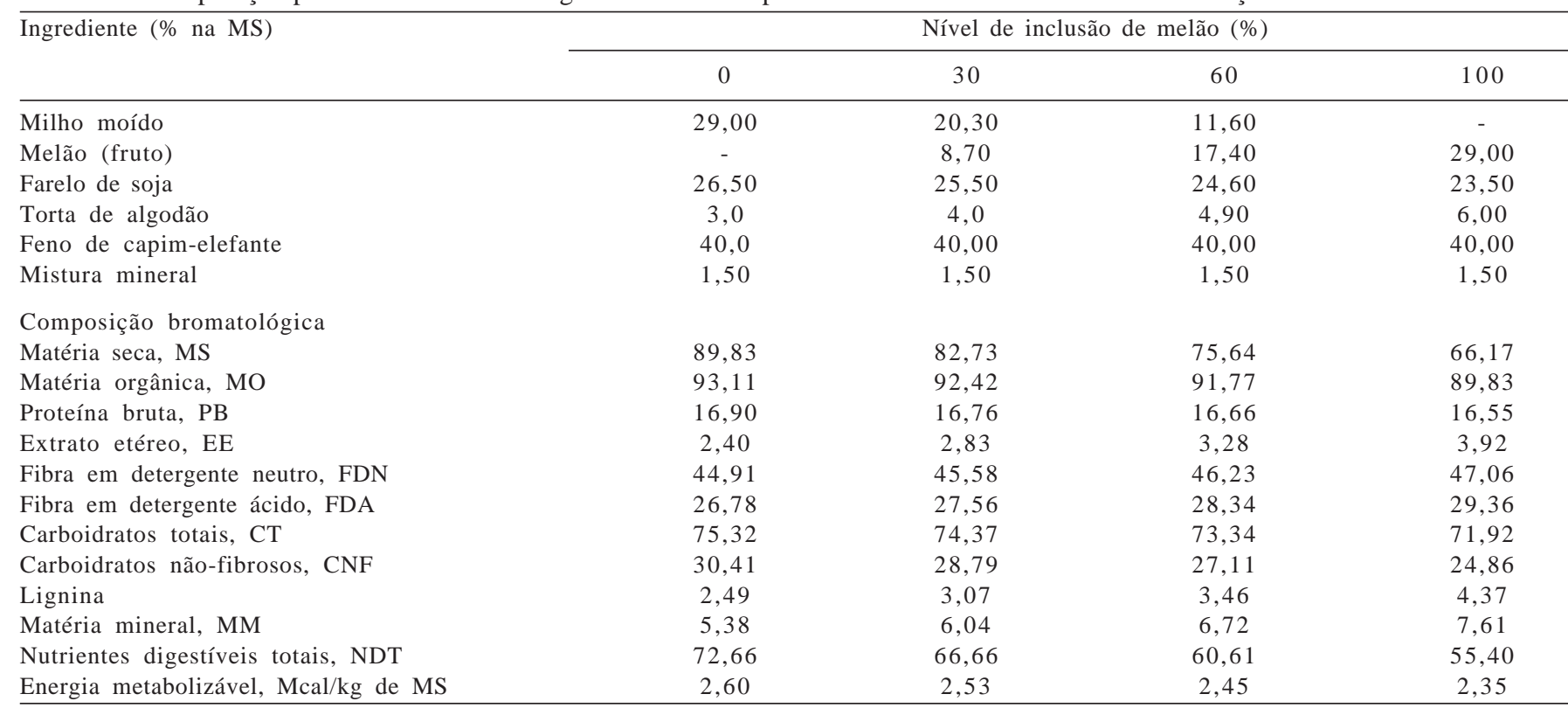

detergente neutro (FDN) e fibra em detergente ácido (FDA), foi utilizada a metodologia descrita por Van Soest et al. (1991) e recomendada pelo fabricante do aparelho ANKOM Technology ${ }^{\circledR}$. Os saquinhos para análise foram adaptados utilizando-se sacos de polipropileno (tecido-não-tecido, gramatura $100 \mathrm{~g} / \mathrm{m}^{2}$ ), Os carboidratos totais (CT) foram determinados segundo Sniffen et al. (1992), aplicando-se a equação CT = 100 - (\%CP + \%EE + \%MM), e os carboidratos não-fibrosos, de acordo com Hall et al. (1999), pela equação $\mathrm{CNF}=\% \mathrm{CT}-\% \mathrm{FDNCp}$.

Os animais foram abatidos por insensibilização por atordoamento, seguida de sangria, com secção das artérias carótidas e veias jugulares. As carcaças foram transferidas para uma câmara de refrigeração, penduradas em ganchos apropriados pelas articulações tarsometatarsianas, com distanciamento de $17 \mathrm{~cm}$, permanecendo em temperatura de $5{ }^{\circ} \mathrm{C}$ por 24 horas. Após esse período, as carcaças foram seccionadas ao meio com serra elétrica e a meia-carcaça esquerda dividida em cinco cortes: pescoço, paleta, costela, lombo e perna.

Para análise da composição centesimal da carne, utilizou-se o músculo semimembranosus das pernas dissecadas. As amostras, após a retirada da gordura externa visível, foram submetidas às determinações de umidade, proteína, gordura e cinzas, realizadas de acordo com as normas da AOAC (1990), após homogeneização em multiprocessador.

A análise sensorial foi feita por dez provadores treinados, cinco do sexo feminino e cinco do sexo masculino. As avaliações sensoriais foram realizadas no músculo longissimus dorsi de cada meia-carcaça esquerda do animal, dividido em pequenos cubos de $2 \mathrm{~cm}$ de comprimento, os quais foram salgados com $1,5 \%$ de sal em relação ao peso de cada um e, em seguida, assados em grill com temperatura de $107^{\circ} \mathrm{C}$. Depois de assadas, as amostras de cada tratamento foram acondicionadas em pequenos recipientes fechados para conservar o aroma da carne e codificados com três números.

Em seguida, procedeu-se à degustação da carne, que foi dividida em quatro séries, sendo duas por dia. Em cada uma, o degustador recebia quatro amostras por tratamento, para avaliação das características sensoriais (aroma, maciez, suculência, sabor e avaliação global), e indicava com um traço vertical em uma escala hedônica de oito pontos a intensidade de cada atributo sensorial para cada respectivo código da amostra, adaptado de Larmond (1979) e Madruga et al. (2000).

A escala variava, para a característica odor, de extremamente fraco (1) a extremamente forte (8); maciez, de extremamente macio (1) a extremamente duro (8); para o atributo suculência, a escala foi de extremamente seco (1) a extremamente suculento (8); no quesito sabor, a característica variou de extremamente fraco (1) a extremamente forte (8) e, na avaliação global, que correspondia à soma dos atributos de qualidade que contribuirão na determinação de aceitação do produto, variou de desgosto extremamente (1) a gosto extremamente (8). Para que o sabor da amostra anterior não interferisse na avaliação da próxima amostra, foram servidos para os degustadores água mineral e biscoitos entre uma degustação e outra. 
Foi efetuada análise de variância nos dados relativos à análise sensorial e, para a composição centesimal, utilizou-se a análise de regressão aplicando-se o teste t de Student, a 5\% de probabilidade. As análises estatísticas foram realizadas com auxílio computacional do programa SAEG(2001).

\section{Resultados e Discussão}

$\mathrm{Na}$ composição centesimal do músculo semimembranosus dos ovinos Morada Nova submetidos às dietas com diferentes níveis de frutos-refugo de melão (Tabela 3), as porcentagens de matéria seca, matéria mineral, proteína e lipídios não foram influenciadas $(\mathrm{P}>0,05)$ pelos níveis de substituição do milho por melão na dieta. De acordo com Zeola et al. (2004), a composição centesimal da carne de cordeiros apresentam valores médios de 75\% para a umidade, $19 \%$ para proteína, $4 \%$ para gordura e 1,1\% para as cinzas, porém esses valores podem variar de acordo com o peso de abate, o estado de engorduramento, a idade do animal e a natureza da dieta.

Os resultados observados neste trabalho para composição centesimal estão próximos aos encontrados na literatura (Costa et al., 2009; Madruga et al., 2005; Zeola et al., 2004; Perez et al., 2002; Horcada et al., 1998) e indicam que a carne é de boa qualidade nutricional.

$\mathrm{Na}$ avaliação dos atributos sensoriais da carne, nenhuma característica foi influenciada $(\mathrm{P}>0,05)$ com adição de melão na dieta. Para os atributos de suculência, sabor e aceitação global foram obtidos os valores de 4,85; 4,78 e 5,15 , respectivamente. Essas características organolépticas associadas à maciez determinam a sensação agradável ou desagradável que provoca a aceitação ou a recusa pelo consumidor.

$\mathrm{O}$ aroma da carne não diferiu $(\mathrm{P}>0,05)$ entre os níveis de inclusão de melão na dieta. Neste trabalho, o teor de gordura no músculo não variou entre as dietas (0, 30, 60 e $100 \%$ ), o que possivelmente explica a semelhança entre as notas obtidas para esta qualidade sensorial, que variaram de 4,52 a 4,95. De acordo com Madruga (1997), o aroma da carne está diretamente relacionado ao teor de gordura presente no músculo.

As notas atribuídas à maciez da carne não diferiram entre as dietas contendo melão, provavelmente devido à quantidade de gordura intramuscular $(38,00 ; 36,00 ; 44,00$ e 36,00 g) presente nos músculos, que não diferiu entre os grupos. Segundo Pacheco et al. (2005), existe correlação entre a quantidade de gordura intramuscular e a maciez da carne.

A suculência da carne não diferiu significativamente $(P>0,05)$ entre os grupos. A suculência depende da sensação de umidade nos primeiros movimentos mastigatórios, ou seja, da liberação de líquido pela carne. A sensação de suculência é mantida pelo teor de gordura da carne (Hawrysh et al., 1985; Embrapa, 1999), fato que provavelmente explica as notas atribuídas a esta característica sensorial, que variaram de 4,41 a 5,12, permanecendo acima da média na escala hedônica. De acordo com Kemp et al. (1981), carcaças com maiores conteúdos de tecido adiposo possuem carne mais macia e suculenta. Priolo et al. (2002), estudando os efeitos da alimentação à base de concentrado ou forragem sobre as características da carcaça e da carne de cordeiros Ile de France, verificaram que as carnes mais macias e suculentas provinham de carcaças com maior teor de gordura.

Comparando resultados descritos na literatura (Pinheiro et al., 2006; Yamamoto et al., 2006; Madruga et al., 2005; Pérez et al., 2002; Ribeiro et al., 2001; Sañudo et al., 1997) e os dados de sensação dos provadores para esse atributo (Tabela 4), a carne pode ser classificada como muito macia, tendo em vista as notas encontradas para maciez. Este fato indica que a carne dos animais Morada Nova alimentados com dietas contendo melão atende às exigências dos consumidores, uma vez que esse atributo é uma das principais características organolépticas procuradas pelos apreciadores de carne.

As notas atribuídas ao sabor e à avaliação global da carne não foram influenciadas pela inclusão do fruto-refugo

Tabela 3 - Composição centesimal do músculo semimembranosus de ovinos Morada Nova alimentados com dietas contendo melão em substituição ao milho moído

\begin{tabular}{|c|c|c|c|c|c|c|}
\hline \multirow[t]{2}{*}{ Variável } & \multicolumn{4}{|c|}{ Nível de inclusão (\%) } & \multirow[t]{2}{*}{ CV (\%) } & \multirow[t]{2}{*}{ Regressão } \\
\hline & 0 & 30 & 60 & 100 & & \\
\hline Umidade, \% & 74,39 & 74,79 & 75,48 & 76,32 & 3,70 & $\mathrm{Y}=75,25^{\mathrm{ns}}$ \\
\hline Matéria mineral, \% & 1,08 & 1,05 & 1,08 & 1,03 & 5,18 & $\mathrm{Y}=1,06^{\mathrm{ns}}$ \\
\hline Proteína, \% & 18,69 & 18,96 & 18,53 & 17,79 & 5,19 & $Y=18,48^{n s}$ \\
\hline Lipídios, \% & 4,44 & 3,69 & 3,33 & 3,56 & 18,79 & $\mathrm{Y}=3,75^{\mathrm{ns}}$ \\
\hline
\end{tabular}

*Significativo a 5\% de probabilidade pelo teste t.

ns = não-significativo.

$\mathrm{CV}=$ coeficiente de variação. 
Tabela 4 - Resultados da análise sensorial da carne de cordeiros Morada Nova alimentados com dietas contendo melão em substituição ao milho moído

\begin{tabular}{|c|c|c|c|c|c|}
\hline \multirow[t]{2}{*}{ Variável } & \multicolumn{4}{|c|}{ Nível de inclusão (\%) } & \multirow[t]{2}{*}{$\mathrm{X} \pm \mathrm{DP}^{1}$} \\
\hline & $0 \%$ & $30 \%$ & $60 \%$ & $100 \%$ & \\
\hline Odor & 4,95 & 4,52 & 4,93 & 4,60 & $4,75 \pm 1,401$ \\
\hline Suculência & 4,80 & 5,08 & 5,12 & 4,41 & $4,85 \pm 1,523$ \\
\hline Sabor & 4,96 & 4,79 & 4,81 & 4,55 & $4,78 \pm 1,413$ \\
\hline Avaliação global & 5,08 & 5,60 & 5,05 & 4,90 & $5,15 \pm 1,572$ \\
\hline
\end{tabular}

${ }^{1}$ Media + desvio-padrão.

de melão na dieta. As notas atribuídas pelos provadores para esses atributos indicam que a carne desses animais, mesmo com maior participação de melão na dieta, teve boa aceitação. Esse resultado favorece a utilização de melão na alimentação de ovinos, já que fatores como aparência, maciez, suculência e sabor da carne influenciam a reação do consumidor em gostar ou não da carne foram positivos. No entanto, esses atributos podem variar de acordo com a idade, o sexo, a raça e a alimentação (Sañudo et al., 2000).

\section{Conclusões}

A adição de melão em substituição ao milho moído na alimentação de cordeiros Morada Nova não influencia a composição centesimal nem as características organolépticas da carne. A carne produzida atende às exigências dos consumidores, assim, o uso de melão nas dietas constitui alternativa para a terminação de cordeiros em regiões produtoras de melão.

\section{Referências}

ASSOCIATION OF OFFICAL ANALYTICAL CHEMISTS AOAC. Official methods of analysis of the Association of official Analyical chemists. 15.ed. Arlington, 1990. $1018 p$.

CAMARGO, R.; FONSECA, H.; GRANER, M. et al. Processamento e conservação de produtos de origem animal: carnes vermelhas e produtos avícolas. In: PEIXOTO, A.M.; TOLEDO, F.F. (Eds.) Tecnologia dos produtos agropecuários. São Paulo: Nobel, 1986. p.137-161.

CAPARRA, P.; FOTI, F.; SCERRA, M. et al. [2006]. Solar-dried citrus pulp as an alternative energy source in lambs diets: efects on growth and carcass and meat quality. Small Ruminant Research. Disponível em: <http://elsevier.com/locatel/ smallruminant>. Acesso em: 20 set. 2006.

COSTA, E.C.; RESTLE, J.; BRONDANI, I.L. et al. Composição física da carcaça, qualidade da carne e conteúdo de colesterol no músculo Longissimus dorsi de novilhas Red Angus super precoces, terminadas em confinamento e abatidas com diferentes pesos. Revista Brasileira de Zootecnia, v.31, n.1, p.417-428, 2002.

COSTA, R.G.; BATISTA, A.S.; MADRUGA, M.S. et al. Physical and chemical characterization of lamb meat from different genotypes submitted to diet with different fibre contents. Small Ruminant Research, v.81, p.29-34, 2009.
DIAS, R.C.S.; COSTA, N.D.; CERDAN, C. et al. Cadeia produtiva do melão do Nordeste. In: CASTRO A.M.G.; LIMA, S.M.V.; GOEDERT, W.J. et al. (Eds.) Cadeias produtivas e sistemas naturais: prospecção tecnológica. Brasília: Embrapa SPI, 1998. p.440-493.

EMPRESA BRASILEIRA DE PESQUISA E AGROPECUÁRIA EMBRAPA. Conhecendo a carne que você consome Qualidade da carne bovina. Campo Grande: Embrapa Gado de Corte, 1999. 25p. (Documentos, 77).

GONZAGA NETO, S.; SILVA SOBRINHO, A.G.; ZEOLA, N.M.B.L. et al. Características quantitativas da carcaça de cordeiros deslanados Morada Nova em função da relação volumoso:concentrado na dieta. Revista Brasileira de Zootecnia, v.35, p.1487-1495, 2006.

HALL, M.B.; HOOVER, W.H.; JENNINGS, J.P. et al. A method for partitioning neutral detergent soluble carbohydrates. Journal Science Food Agriculture, v.79, p.2079-2086, 1999.

HAWRYSH, Z.J.; GIFFORD, S.R.; PRICE, M.A. Cooking and eating-quality characteristics of dark-cutting beef from young bulls. Journal of Animal Science, v.60, n.3, p.682-690, 1985.

HORCADA, A.; BERIAIN, M.J.; PURROY, A. et al. Effect of sex on meat quality of spanish lamb breeds (Lacha and Rasa Aragonesa). Animal Science, v.67, p.541-547, 1998.

KEMP, J.D.L. Effect of feeding systems, slaughter weight and sex or organoleptic properties and fatty acid composition of lamb. Journal of Animal Science, v.51, n.2, p.321-330, 1981.

LARMOND, E. Laboratory methods for evaluation of foods. Ottawa: Food Research Institute/Canada Department of Agriculture, 1979. 432p.

MADRUGA, M.S.; SOUSA, W.H.; ROSALES, M.D. et al. Qualidade da carne de cordeiros Santa Inês terminados com diferentes dietas. Revista Brasileira de Zootecnia, v.34, n.1, p.309-315, 2005.

MADRUGA, M.S. Processamento e características físicas e organolépticas das carnes caprinas e ovinas. In: SEMANA DA CAPRINOCULTURA E OVINOCULTURA BRASILEIRAS, 4., 2004, Sobral. Anais... Sobral, 2004. (CD-ROM).

MADRUGA, M.S.; ARRUDA, S.G.B.; NARAIN, N. et al. Castration and slaughter age effects on panel assessment and aroma compounds of the "mestiço" goat meat. Meat Science, v.56, p.117-125, 2000.

MANTEROLA, B.; CERDA, A.; FORTE, F. et al. Valor nutritivo y uos de resíduos hortifruticulas y agroindustriales en alimentación de ruminantes. In: SIMPOSIO SOBRE UTILIZAÇÃO DE SUBPRODUTOS E RESIDUOS DE COLHEITAS NA ALIMENTAÇÃO DE RUMINANTES. 1992, São Carlos. Anais... São Carlos: Embrapa/Uepae, 1992. p.297-324.

NATIONAL RESEARCH COUNCIL - NRC. Nutrient requirements of sheep. Washington: National Academy Press, 1985. 99p.

OSÓRIO, J.C.S. Características quantitativas e qualitativas da carne ovina. In: REUNIÃO DA SOCIEDADE BRASILEIRA DE ZOOTECNIA, 42., 2005, Goiânia. Anais... Goiânia: SBZ, 2005. p.149-156.

PACHEDCO, P.S.; RESTLE, J.; SILVA, J.H.S. et al. Composição física da carcaça e qualidade da carne de novilhos jovens e superjovens de diferentes grupos genéticos. Revista Brasileira de Zootecnia, v.34, p.1691-1703, 2005. 
PÉREZ, P.; MAINO, M.; TOMIC, G. et al. Carcass characteristics and meta quality of Sullfolk Down suckling lambs. Small Ruminant Research, v.44, p.233-240, 2002.

PINHEIRO, R.S.B.; SILVA SOBRINHO, A.G.S. et al. Características sensoriais da carne de ovinos de diferentes categoriais: In: REUNIÃO ANUAL DA SOCIEDADE BRASIlEIRA DE ZOOTECNIA, 43., 2006, João Pessoa. Anais... João Pessoa: SBZ, 2006. (CD-ROM).

PRIOLO, A.; MICOL, D.; AGABRIEL, J. et al. Effect of grass on concentrate feeding systems of lamb carcass and meat quality. Meat Science, v.62, p.179-185, 2002.

RIBEIRO, E.L.A.; ROCHA, M.A.; MIZUBUTI, I.Y. et al. Carcaça de borregos Ile de France inteiros ou castrados e Hawpshire Down castrados abatidos aos doze meses de idade. Ciência Rural, v.31, p.479-492, 2001.

SAÑUDO, C.; CAMPO, M.M.; SIERRA, I. et al. Breed effect on carcass and meat quality of suckling lambs. Meat Science, v.4, n.4, p.357-365, 1997.

SAÑUDO, C.; ENSER, M.E.; CAMPO, M.M. et al. Fatty acid composition and sensory characteristic of lamb carcasses from Britain and Spain. Meat Science, v.54, p.339-346, 2000 .
SISTEMA DE ANÁLISES ESTATÍSTICAS E GENÉTICAS - SAEG. Viçosa, MG: UFV, 2001. 301p.

SILVA, D.J.; QUEIROZ, A.C. Análise de alimentos (métodos químicos e biológicos). Viçosa, MG: Universidade Federal de Viçosa, 2002. 235p.

SNIFFEN, C.J.; O’CONNOR, J.D.; VAN SOEST, P.J. et al. A net carbohydrate and protein system for evaluating cattle diets: II. Carbohydrate and protein availability. Journal of Animal Science, v.70, n.3, p.3562-3577, 1992.

VAN SOEST, P.J.; ROBERTSON, J.B.; LEWIS, B.A. Methods for dietary fiber, neutral detergent fiber, and nonstarch polysaccharides in relation to animal nutrition. Journal of Dairy Science, v.74, p.3583-3597, 1991.

YAMAMOTO, S.M.; SILVA SOBRINHO, A.G.; SOUZA, H.B.A et al. Características sensoriais da carne de cordeiros alimentados com dietas contendo silagem de resíduo de peixe. REUNIÃO DA SOCIEDADE BRASILEIRA DE ZOOTECNIA, 43., João Pessoa, 2006. Anais... João Pessoa, SBZ, 2006. (CD-ROM).

ZEOLA, N.M.B.; SILVA SOBRINHO, A.G.; GONZAGA NETO, S. et al. Composição centesimal da carne de cordeiros submetidos a dietas com diferentes teores de concentrado. Ciência Rural, v.34, n.1, p.253-257, 2004. 